\title{
Outbreak of Serogroup C Meningococcal Disease Primarily Affecting Men Who Have Sex with Men — Southern California, 2016
}

\begin{abstract}
Srinivas Nanduri, $\mathrm{MD}^{1,2}$; Chelsea Foo, $\mathrm{MPH}^{3,4}$; Van Ngo, $\mathrm{MPH}^{3}$; Claire Jarashow, $\mathrm{PhD}^{1,3}$; Rachel Civen, $\mathrm{MD}^{3}$; Ben Schwartz, $\mathrm{MD}^{3}$; John Holguin, $\mathrm{MPH}^{5}$; Eric Shearer, $\mathrm{MPH}^{6}$; Matt Zahn, $\mathrm{MD}^{6}$; Kathleen Harriman, $\mathrm{PhD}^{7}$; Kathleen Winter, $\mathrm{PhD}^{7}$; Cecilia Kretz, $\mathrm{PhD}^{2}$; How Yi Chang, $\mathrm{PhD}^{2}$; Sarah Meyer, $\mathrm{MD}^{2}$; Jessica MacNeil, $\mathrm{MPH}^{2}$
\end{abstract}

On September 2, 2016, this report was posted as an MMWR Early Release on the MMWR website (http://www.cdc.gov/mmwr).

During March 4-August 11, 2016, 25 outbreak-associated cases of meningococcal disease, including two deaths $(8 \%$ case-fatality ratio), were reported in Southern California. Twenty-four of the cases were caused by serogroup C Neisseria meningitidis $(\mathrm{NmC})$ and one by $N$. meningitidis with an undetermined serogroup (Figure). On June 24, 2016, in response to this increase in $\mathrm{NmC}$ cases, primarily among men who have sex with men (MSM) in Los Angeles County, the city of Long Beach, and Orange County, the California Department of Public Health (CDPH) issued a press release and health advisory, declaring an outbreak of $\mathrm{NmC}$ in Southern California (1).

During 2010-2016, clusters of NmC among MSM were reported in the United States in New York City (2010-2013), Los Angeles County (2012-2014), and Chicago (2015-2016), as well as in Europe, with clusters in Berlin (2012-2013) and Paris (2014) (2-4). In response to these clusters, the affected jurisdictions recommended vaccination with serogroup Ccontaining meningococcal vaccines. In the previous Los Angeles County cluster during 2012-2014, MenACWY vaccination recommendations were based on risk behaviors identified, and included MSM with human immunodeficiency virus (HIV) infection and MSM, regardless of HIV status, who regularly had close or intimate contact with multiple partners or sought partners through the use of digital applications ("apps"), particularly those who shared cigarettes or marijuana, or used illegal drugs. This vaccine recommendation had remained in place in Los Angeles County since that time.

The exact population size of MSM living in the currently affected communities is unknown. Denominators for calculating attack rates were estimated by using the US Census Bureau's American Community Survey for males aged $\geq 18$ years ( $5-7)$.

Of the 25 cases in the current outbreak, $23(92.0 \%)$ patients were male, 20 (87.0\%) of whom self-identified as MSM. Among MSM, eight (40.0\%) reported Hispanic ethnicity, consistent with the proportion of Hispanic persons among the overall population of the three jurisdictions combined, and the median age was 32 years (range: $17-74$ years). The estimated $\mathrm{NmC}$ attack rate among MSM in the three affected jurisdictions was 6.4 cases per 100,000 MSM which is more than 50 times the incidence of meningococcal disease among males aged $\geq 18$ years in the United States in 2015 ( 0.12 cases per 100,000 population) (CDC, unpublished data, 2016).

Ten of the 25 cases occurred among residents from Los Angeles County, seven in residents from Long Beach, seven in residents from Orange County, and one in a resident of another state who traveled to Los Angeles in the week before illness onset. Two of the patients were known to have HIV infection. No direct epidemiologic linkages, geographic concentration, visits to common events or venues, or behaviors such as drug use or multiple sexual partners were consistently identified among the MSM patients. Through whole genome sequencing, isolates from 16 patients were identified as belonging to sequence type ST-11 and clonal complex CC11 with an identical molecular profile (PorA P1.5-1, 10-1; FetA F3-6; PorB 2-285). Whole genome sequencing results for the remaining isolates are pending.

On July 26, 2016, given the absence of identifiable risk groups among MSM, in contrast to the previous Los Angeles County cluster (2012-2014), local health departments in Los Angeles County, Long Beach, and Orange County, along with San Diego County, in consultation with $\mathrm{CDPH}$, expanded their vaccination recommendations to include all MSM regardless of risk behaviors, residing in the respective jurisdictions (8). Outreach and vaccination activities are ongoing in collaboration with community-based organizations, pharmacies, and health care providers. The Advisory Committee on Immunization Practices recently discussed use of MenACWY vaccine among MSM and HIV-infected persons (http://www. cdc.gov/vaccines/acip/meetings/meetings-info.html) and in June 2016 recommended that all HIV-infected persons be routinely vaccinated with MenACWY (http://www.cdc.gov/ vaccines/acip/index.html).

Increased awareness of the signs and symptoms of meningococcal disease (http://www.cdc.gov/meningococcal/ about/symptoms.html) and prompt early case recognition among health care providers are critical. During investigations of meningococcal disease caused by any serogroup, health departments are encouraged to assess HIV status of all patients and sex of sex partners in cases occurring among males aged $\geq 16$ years (3). If permitted by state law, state health departments are asked to complete a supplemental case report form (available at http://www.cdc.gov/meningococcal/ 


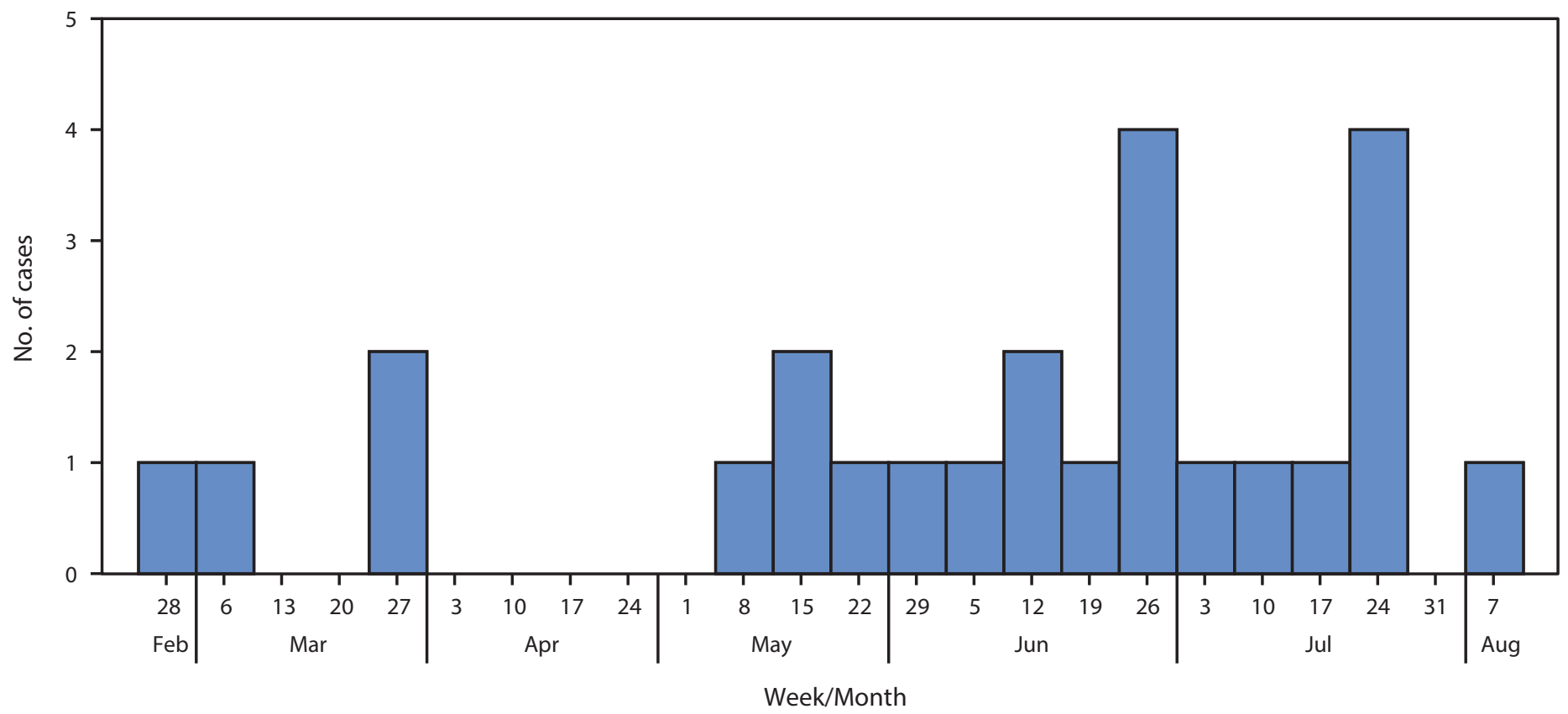

surveillance/index.html) for all cases of meningococcal disease occurring among MSM, submit the forms to CDC via secure e-mail (meningnet@cdc.gov) or via secure fax (404-315-4681), and submit any available isolates to CDC for whole genome sequencing. In addition, health departments should assess $\mathrm{NmC}$ patients for epidemiologic linkages to the Southern California region to identify additional cases possibly related to this ongoing outbreak.

\section{Acknowledgments}

Los Angeles County Department of Public Health; Los Angeles County Public Health Laboratory; Long Beach Department of Health and Human Services Epidemiology Program; Long Beach Public Health Laboratory; Orange County Health Care Agency; Orange County Public Health Laboratory; California Department of Public Health; California Department of Public Health Microbial Diseases Laboratories; Jennifer Kyle, California Department of Public Health Microbial Diseases Laboratories; Margia Ambroise, CDC Epidemiology Elective Program; Melissa Whaley, Xin Wang, CDC Bacterial Meningitis Laboratory.

\footnotetext{
${ }^{1}$ Epidemic Intelligence Service, CDC; ${ }^{2}$ Division of Bacterial Diseases, National Center for Immunization and Respiratory Diseases, CDC; ${ }^{3}$ Los Angeles County Department of Public Health; ${ }^{4}$ Council of State and Territorial Epidemiologists Applied Epidemiology Fellowship; ${ }^{5}$ Long Beach Department of Health and Human Services; ${ }^{6}$ Orange County Health Care Agency; ${ }^{7}$ California Department of Public Health.

Corresponding author: Jessica MacNeil, jmacneil@cdc.gov.
}

\section{References}

1. California Department of Public Health. CDPH issues health advisory for meningococcal disease. Sacramento, CA: California Department of Public Health; 2016. http://www.cdph.ca.gov/Pages/NR16-037.aspx

2. Aubert L, Taha M, Boo N, et al. Serogroup C invasive meningococcal disease among men who have sex with men and in gay-oriented social venues in the Paris region: July 2013 to December 2014. Euro Surveill 2015;20:pi:21016. http://dx.doi.org/10.2807/1560-7917. ES2015.20.3.21016

3. Kamiya H, MacNeil J, Blain A, et al. Meningococcal disease among men who have sex with men-United States, January 2012-June 2015. MMWR Morb Mortal Wkly Rep 2015;64:1256-7. http://dx.doi. org/10.15585/mmwr.mm6444a6

4. Koch J, Hellenbrand W, Schink S, et al. Evaluation of a temporary vaccination recommendation in response to an outbreak of invasive meningococcal serogroup $\mathrm{C}$ disease in men who have sex with men in Berlin, 2013-2014. Euro Surveill 2016;21:12-22. http://dx.doi. org/10.2807/1560-7917.ES.2016.21.5.30122

5. US Census Bureau. American Community Survey. Washington, DC: US Census Bureau; 2016. https:/www.census.gov/programs-surveys/acs/

6. Purcell DW, Johnson CH, Lansky A, et al. Estimating the population size of men who have sex with men in the United States to obtain HIV and syphilis rates. Open AIDS J 2012;6:98-107. http://dx.doi. org/10.2174/1874613601206010098

7. Grey JA, Bernstein KT, Sullivan PS, et al. Estimating the population sizes of men who have sex with men (MSM) in US states and counties using data from the American Community Survey. JMIR Public Health Surveill 2016;2:e14. http://dx.doi.org/10.2196/publichealth.5365

8. California Department of Public Health. New vaccine recommendations to contain the outbreak of meningococcal disease in Southern California: what providers need to do. https://www.cdph.ca.gov/HealthInfo/discond/ Documents/CDPH-MSM-mening-health-advisory-Aug16-2016.pdf 